\title{
Critical reflections on performing arts impact evaluations
}

\author{
Dr Nicola Williams-Burnett ${ }^{1}$ and Dr Heather Skinner ${ }^{2}$ \\ ${ }^{1}$ Cardiff Metropolitan University \\ ${ }^{2}$ Institute of Place Management \\ nwilliams-burnett@cardiffmet.ac.uk \\ heatherskinnercorfu@gmail.com
}

\begin{abstract}
Purpose - To present a critically reflective account of the process of conducting an impact evaluation of a dance-theatre company's staged productions and workshops.

Approach - There are two main approaches: The introspective critical reflection on the process of performing an impact evaluation; and the drawing / colouring methods used to perform it.
\end{abstract}

Findings - It is more difficult to provide impact evaluations of the soft rather than hard outcomes of publicly funded performance arts. The engagement of third-party evaluators may help overcome the challenge that many 'accepted' approaches are outwith the skill or financial resources of smaller non-profit organisations.

Research limitations/implications - although based on a single case, we believe that we evidence how the use of innovative methodologies may be more appropriate to performing arts impact evaluations, even those less familiar to management researchers.

Practical implications - This paper offers insights into various methods of impact evaluation that may be of use to smaller non-profit arts organisations who may be constrained by limited skills and financial resources.

Originality - This paper provides an original contribution to understanding innovative methodologies to perform arts impact evaluations, particularly those assessing soft outcomes, and a contribution in recognising the role of academic researchers in performing such evaluations.

Keywords: dance-theatre; soft outcomes; impact evaluations; drawing and colouring methodologies

Article Classification: Research article 


\section{Critical reflections on performing arts impact evaluations}

\section{Introduction}

In a climate typified by constrained resources and funding cuts, attempting to evidence the value of an arts or cultural project through an evaluation of its impact has become of critical importance to organisations that undertake such projects. Many such attempts remain focused on hard outcomes that are objective and quantifiable, because to some extent, not only are these more readily able to be measured, but also because measurements tend to be more welcomed, sought, and highly prized by funders than evaluations of soft outcomes which tend to be more subjective, and based more on emotional and experiential dimensions (Fillis, 2011). Against this background, this research project has attempted to offer practical insights into various methods of impact evaluation that may be of particular use to smaller non-profit arts organisations, the ones most constrained by limited skills and financial resources. This paper also provides insights into a drawing methodology that may help assess soft outcomes of arts and cultural projects involving young children. Through a critical introspective account of the process by which the impact evaluation in this particular case was conducted, the paper also offers a contribution in recognising the role of third-party evaluators, specifically academic researchers, in performing such impact evaluations.

In the UK towards the end of 2013, following year upon year of cuts, it was predicted that local council 'quality of life' funding, which includes funding for the arts, 'will largely disappear in the next three years' (Butler, 2013). In May 2015, with continuing austerity measures in the UK, it was reported that there had been a 36\% cut to Arts Council England's government grant since 2010 (Youngs, 2015), and in Australia protests against the ' $\$ 105 \mathrm{~m}$ budget cut to the top arts funding body, Australia Council, were held around the nation' (Tan, 2015). The recent UK government 2015 Autumn Statement and spending review did not evidence the massive cuts some had forecast to Arts Council funding. Instead, funding of Arts Council England, and national museums and galleries will be funded at the same level in 2019-20 as in 2015, although in real terms this equates to an overall 5\% reduction in funding (Brown, 2015). However, there remain regional cuts in arts funding at a local council level, for example, Birmingham City Council has suffered a recent $25 \%$ cut, which follows cuts of $20 \%$ in 2013 and $17 \%$ in 2010, and foresees its arts budget cut by a further $£ 1.25$ million by 2020 (Brennan, 2015). 
It has been recognised that 'one of the major strategic challenges for cultural organisations is to balance all the economic issues and constraints such as the allocation of scarce resources with the importance of meeting artistic and cultural goals' (Hume and Mort, 2008:312). Indeed, many individuals and organisations involved in the creative and cultural industries are reliant upon either public money or charitable endowments to fund their artistic endeavours. Because of the nature of this type of funding, such individuals and organisations must find ways of attempting to evidence that past funding has been worthwhile in order that they may then improve their chance of securing future funding.

The authors of this article were engaged with undertaking a third party evaluation of the impact on young schoolchildren of a dance-theatre company's staged theatre productions and school-based workshops in order to strengthen that company's bids for further funding. This company had very recently performed their stage dance-theatre show in 4 different counties within the region for which we were asked to undertake this impact evaluation, and in those counties also conducted participatory dance workshops in 14 primary schools involving 617 schoolchildren aged 6-7 years.

The focus of the remainder of the paper is on the process by which this evaluation was performed. Impact evaluations form a central part of many such organisations' marketing strategies, and are relied upon heavily not only when positioning the organisation in an increasingly competitive funding arena, but also when positioning the service that is offered by the organisation to consumers.

This paper does not intend to delve into the value-laden arguments concerning whether or not the impact of the creative and cultural industries should be measured, nor is it concerned with simply presenting results of measuring the impact of such endeavours. Rather, its aim is to present a critically reflective account of the process undertaken by the authors when conducting an impact evaluation exercise. Ambiguity within the title of the paper is therefore intentional, as this research is concerned with not only evaluating the impact of the performing arts, but also with the act of performing arts impact evaluations.

In terms of relevance to the domain of arts marketing, as categorised by O'Reilly (2011), this paper will contribute to the areas of cultural economics (which includes impact analysis) and 
the performing arts. In terms of this paper's methodological contribution, we have adopted not only an introspective critical reflection on the process of performing an impact evaluation of the arts, we have also employed creative drawing and colouring methodologies in performing this evaluation, suitable to the young age of the research participants (6-7 years), in keeping with using creative methods that may be less familiar to business and management researchers, but which may better 'mirror those found in arts marketing practice' (Fillis, 2011:14).

\section{Evaluating performing arts experiences}

When considering the various research approaches applied to such issues in the extant literature we found a number of relatively recent studies that have incorporated not only a consideration of the experiential aspect of audience engagement with the performing arts, but also some evidence of the use of more creative research methods.

Hume and Mort (2008) propose that in addition to evaluating the core performance and show experience along with peripheral aspects of service quality, research should include an evaluation of value and customer satisfaction. So, for example, in their study, questions regarding service quality focused on rating core issues of the service experience such as: 'the technical aspects of the show, the actors, stage and show performance', whether the show was deemed 'stimulating, entertaining and professional', and whether the show was what audience members expected to experience, along with the more peripheral aspects of the service including: 'access, parking and transport to the venue', organisation within the venue, and behaviour of 'ticketing, seating, cloaking and refreshments' staff at the venue (p316).

Recognising the shift towards service-dominant logic, Conway and Leighton (2012:37) understand that 'this is related to experiential marketing in which contexts, emotions and symbolic aspects of customer experiences are significant', yet with regard to experiential marketing in the arts and cultural sectors 'the role and expectations of the visitor as an active, skilled and discerning participant in the consumption process have been neglected and models of consumption have tended to treat consumer behaviour somewhat narrowly'. Similarly Wood and Moss (2015, pp 45-47) propose that such research should be framed 'within the concept of experiential marketing' because 'it is the live event experience which creates an emotional response, further asserting that there appears to be a 'clear link between emotional response (to the event experience) and satisfaction'. Endeavouring to capture insights into the 
emotions and experience of such participatory and active audience members, Wood and Moss included use of the day reconstruction method in their research, although recognising that with such methods, attention needs to be paid to issues of participants memories of the staged event.

'Emotions are stored in experiential memory which is short lived, memories of emotions are stored in episodic memory and beliefs, formed partly due to those emotions, are stored in semantic memory. The experienced emotion can therefore be different to the remembered emotion and both will affect beliefs and possibly, attitudes and behaviour. This understanding already has implications for experiences at events and how best to capture data on the emotions generated by those experiences' (Wood and Moss, 2015:48).

In their study of a participatory performing arts programme in schools, Jones, Murphy, Salmon, Kimberlee and Orme (2004:351) focused on evaluating The Rock Challenge 'a school-based performing arts programme that aims to promote healthy lifestyles amongst secondary school students' thus focusing on students aged between 11-18. This programme is implemented at the school level, and teams of students from different schools enter nationwide competitions, and are given the creative freedom within their school to create 'a dance-or drama-based performance that is accompanied by music and lighting effects'. Thus the implementation of the programme varies at a local level, and evaluation focused on the 'process' of implementing the programme rather than on performance or participation.

Douglas, Warwick, Whitty and Aggleton (2000:209) considered evaluation issues of Theatre in Education (TIE) programmes for health education, focusing on an initiative aimed at young people aged between 11-21. These authors used an evaluative case study, because 'traditional research methods were thought to be not well suited to evaluate what was a creative and artistic endeavour', and based this decision on earlier suggestions about the type and appropriateness of different research methods in such cases:

'Where there are some instruments that purport to measure creativity, the applicability of those instruments in diverse situations is at least open to question. Thus a program attempting to make students or clients more creative might do better to document in detail the activities, behaviours, thoughts and feelings of participants than to administer some instrument' (Patton, 1987:37). 
Fineberg's (2015) blog focuses on arts programmes that are also embedded within an educational curriculum which can impact on students' learning of basic arts practices. When teachers evaluate these initiatives they can make observations that a student is 'applying to an academic class what has been learned as part of an arts session or total experience'. For artists, indeed that the very "notion of "evaluation" becomes unsettling and intrusive for many and at times it can elicit real resentment'. Therefore Fineberg believes that both educators and artists should both bring their different strengths to provide useful insights to the evaluation process for third party evaluators.

\section{Evaluating impact}

Evaluating the impact of cultural endeavours tends to measure inputs, outputs and outcomes (Lingayah, McGillivray and Raynard, 1996) from the perspective of cause and effect (Landry, Bianchini, Maguire and Worpole, 1993). Such a focus can, in no small part, be attributed to the way the cultural industries are funded, where public money or charitable endowments can often be the only source of funding for many non-commercial creative and artistic endeavours (Caust, 2003) which in turn tends to require accountability for the use of such funds (Fineberg, 2015; Fillis, 2011; Kelly and Kelly, 2000) with organisations in the cultural and creative industries having to 'find quantifiable ways to show how their service makes a difference' (Anderson, 2008:31). The practice of evaluation therefore tends to focus on the use of methods that can demonstrate 'the contribution of arts and culture to the social and economic objectives of national and local government, and other key partners' (Reeves, 2002:1), where 'contribution' tends to be equated to impact, which in turn, becomes a construct that not only can, but should be measured, setting the stage for:

'a generation of impact studies, and other analyses commissioned by local authorities and other public funding agencies, which sought to document and argue the case for the role of the arts and creative industries as important agents for economic development and urban renewal, and begin to measure this impact in quantitative terms' (Reeves, 2002:7-8).

Impact in these terms may also be measured indirectly, for example, in terms of additional economic activity brought about from those participating in cultural activity also contributing economically to secondary activities such as tourism or retail consumption (Reeves, 2002). 
Importantly, social impact is less well defined than economic impact, and is thus more difficult to evaluate.

There are also challenges to be faced when considering the differences in the language used when considering the arts, cultural industries, and the performance arts etc. where no single accepted all-encompassing definition of the wide range of activities exists (Reeves, 2002), and where the language of the arts as performance may clash with the language of business as evaluation (Fillis, 2011) or educational evaluation (Fineberg, 2015). Moreover, the subjective nature of social outcomes makes these harder to measure than either outputs or inputs (Butcher and Marsden, 2004; Lingayah et al., 1997), yet there remains an assumption in much of the literature that 'measurement' is an unassailable construct and its necessity 'is agreed upon by the majority of authors' (Wood, 2005:38). Some literature questions whether o it is appropriate to 'measure' at all (Kelly and Kelly, 2000), with arguments tending to be based on the 'arts for art's sake' premise that there is an inherent value to the creative and cultural arts which should not be evaluated in purely rational economic terms (Caust, 2003). Even when evaluating impact on the lives of performance arts participants or audiences, the literature is polarised at one extreme with purely quantitative evaluations (Brewster, 2014), and highly qualitative evaluations at the other (Walmsley, 2013). Fillis (2011:16) believes it is appropriate for 'arts marketing research to embrace both hard and soft dimensions of evaluation' and that, because 'the creation of an artwork involves many creative inputs and its success will be judged in both qualitative and quantitative terms, depending on who is doing the evaluating'.

When impact is 'measured' quantitatively, concepts such as 'engagement' with the arts can also consider whether individuals are engaged as creative or receptive participants, with a recent Australian study (Australia Council for the Arts, 2010) finding that younger people (aged 15-24) tended to be more heavily engaged as creators whereas older people (aged 3564) tended to be more heavily engaged as consumers of the arts. Data from the United States reveals that younger school aged children are more likely to participate in performing arts in school than older pupils, with many studies finding positive associations between school arts participation and desired behavioural and academic outcomes (Child Trends, 2010). Daykin, Orme, Evans, Salmon, McEachran and Brain (2008) undertook a systematic review of articles published between 1994-2004 considering performing arts activities undertaken in school and community settings with young people aged 11-18. Their review found high levels of 
participation by young people in activities such as drama, and that participation in such activities was often reported as evidencing health and behaviour benefits amongst this age group.

Anderson (2008) points out that, when measuring soft outcomes, while 'the most commonly used method has been to use case study examples showing "the journey" a person has experienced whilst working with an organisation', such methods are not usually deemed by funders to provide sufficient evidence of impact. Instead, Anderson (2008:36) identifies the 'four major soft outcome measurement systems in the present marketplace':

- The Outcomes Star - that captures 'a client's "Journey of Change"' (Anderson, 2008:32).

- The Spirit Level - a tool to profile the quality of life of service users

- The Rickter Scale - which service users themselves score, where achievements can be recorded in areas important to the service user (Anderson, 2008).

- The SOUL record - 'Soft outcomes for adults are divided into three main areas: "attitude", "personal / interpersonal" and "practical", whereas for children and young people, soft outcomes may be measured against the five outcome areas of Every Child Matters (i.e. Being Healthy, Staying Safe, Enjoying and Achieving, Making a Positive Contribution, Economic Well-Being)' (Anderson, 2008:35).

The Paul Hamlyn Foundation, 'one of the UK's largest independent grant-giving organisations' (www.phf.org) has similarly produced an Evaluation Resource Pack (Paul Hamlyn Foundation \& NIACE, n.d.). This pack recognises not only that a lack of perceived skills in evaluation can lead managers in some organisations to outsource this activity, but also that objective third party impact evaluation can be a condition of funding. The pack includes information specifically targeting the voluntary sector about both the principles and practices of evaluation, stressing that 'it's a way of collecting evidence and analysing it so that you can demonstrate to others whether your project met or exceeded your expectations' (p14). This pack describes various methods of researching impact (p27), such as: Surveys and Questionnaires; Face-to-Face Interviews; Telephone Interviews; Focus Groups; Users' Forums; Listening Campaigns; Doing a SWOT Analysis; Appreciative Inquiry; Open Space; Conducting a Participatory Review; Graffiti Walls; Storyboards; Story-telling and Testimonies; Logbooks, Blogs and Webchats; Photo Diaries and Scrap Books; Video and Audio Diaries; Feeling Boxes; Performances and Presentations. While some of these methods 
will be familiar to management and marketing researchers, others tend to be less used or not used at all outside of research in the cultural and creative industries. Lawrence and Philips (2002:430) have called for management researchers 'to take the commercial production of culture more seriously' although recognising that this may require a major shift towards methods and methodologies more in use in fields such as art and literature that tend to be less familiar to business and management researchers. This also strengthens the argument for bringing in third party external evaluators, particularly for arts programmes that are involved in educational settings, who may have wider skills in a variety of different research methods (Fineberg, 2015).

Moreover, while recognising that 'in the current policy context evaluation has become a technocratic "hoop" for arts organisations to jump through in an endless mutual narrative driven by cultural policy, instrumentality and accountability' there is a call to move away from 'toolkit' based evaluations towards a more 'informative, generative, critical and nonpartisan' approach that would rethink 'evaluation as a critical practice', and lead to a rethinking of 'the relationship between participatory arts and cultural policy' (Rooke, 2014). While much of the literature on evaluation within the arts and cultural industries literature remains focused on the debate between arts for arts sake vs economic rationality of a measurement of the 'value' of the arts, the main themes arising in the literature are summarised in Table 1:

\section{Table 1: Main themes arising in the arts evaluation literature}

\section{Method}

Two research issues will be addressed within this article: The process of performing an impact evaluation of the arts, which was undertaken using introspective critical reflection; and the methods used to perform the evaluation.

Our task was to provide a dance-theatre company with an evaluation of the impact of their work, both in terms of staged theatre productions and school-based workshops undertaken with children aged 6-7.

The key advantages of using some of the evaluatory methods outlined by Anderson (2008) such as the Outcomes Star, Spirit Level, Rickter Scale, or Soul Record are that they assess 
soft outcomes. However, a key disadvantage is that these are proprietary, and therefore tend to cost more than small arts organisations can afford to pay, even though Fineberg (2105) identifies that some funding does include an amount specifically for evaluation.

Of the other methods identified in the literature review, notably by the Paul Hamlyn Foundation \& NIACE, (n.d.), many were simply not considered appropriate for this project because of the age of the children would have precluded their use. Moreover, we wanted to purposively choose a more artistic and creative method for the evaluation, as deemed more appropriate by Lawrence and Philips (2002) and Fillis (2011). Fineberg (2015) also stresses the importance of the size and scale of the evaluation to be fit for purpose so that the tail does not end up wagging the dog. Therefore a small scale qualitative approach was deemed appropriate. We then employed a method of collecting data through colouring in that was deemed suitable to undertaking research with young children. This method was designed to result in the assessment of soft outcomes relating to the identification of relatively simple emotions that the child participants may have experienced during the workshops and performances.

At the request of the dance-theatre company, our original research design also included a plan to further assess impact by gathering the views of teachers from schools that had participated in the workshops and attended the performances. A relatively short Likert-scale questionnaire was designed that attempted to evaluate the extent to which teachers believed attending the performance and participating in the workshops had enabled the children to appear to be more confident, more creative in the classroom and playground, able to express themselves more clearly, appear more alert in class, had a positive impact on the children's play and on their behaviour. It also asked about the extent to which teachers believed the children enjoyed the opportunity to be involved with the arts in general, and with dance in particular, enjoyed watching the performances, enjoyed the experience of going to the theatre, and enjoyed the overall experience of engaging with the dance-theatre company. Further questions asked teachers about their perceptions of the overall effect on the school of engaging with the dancetheatre company, and on their own performance as teachers, including questions about their own confidence levels in the classroom, and in particular their confidence in engaging children with becoming more active in class. However, despite numerous contacts from both the dance-theatre company and the researchers, only 5 teachers completed the questionnaire. 
The research approach we adopted for the impact evaluation was discussed and agreed in advance with the dance-theatre company. As it involved researching the views of young children, we ensured adherence to an appropriate ethical approach to gathering data in keeping with both the university and various schools' ethical policies. Our choice of method was also based on a consideration that children may not openly discuss their feelings when in a group environment and may not fully understand what is happening. We chose therefore not to use any method that may cause distress or upset for some of the children as they either may not wish to discuss their feelings or indeed may not comprehend what is happening. We also understood that participating in any form of research may be a completely new experience for them. We were also keen to minimise any response bias where participants might respond in a manner that they think they should respond because they think they are being 'good'. We therefore realised that creative but also appropriate methods of data needed to be identified, along with ways to connect with the children using a method that they were familiar with, were comfortable and had experience of using. Interestingly, the specific drawing method we employed in our impact evaluation is not identified in any of the resources identified as specifically appropriate to measuring soft outcomes.

Drawing methodologies are not a new phenomenon, but are predominately confined to research studies where children are the main participants (Guillemin, 2004) possibly because children tend to enjoy drawing and their drawings can act as a form of communication where sometimes words may fail them (Kuhn, 2003). Unlike adults who may get embarrassed when asked to draw and believe that as an adult they cannot draw very well (Guillemin, 2004; Morgan, McInerney, Rumbold and Liamputtong, 2008), the use of drawing can allow a child to become more involved with the research and create an element of fun, and gives a child time to answer the question that has been put forward by the researcher (Punch, 2002). Drawing is a non-invasive form of data collection that can access data from vulnerable members of society such as children without intruding into their personal spaces (Morgan et al., 2008). Colour is an essential part of everyday life (Hemphill, 1996) and can awaken emotions and affect a person's mood (Boyatzis and Varghese, 1994; Haber and Hershenson, 1973; Hemphill, 1996; Wexner, 1954). The use of colour is a prominent feature in children's daily lives (Boyatzis and Varghese, 1994), and children as young as three can connect colour and emotion (Zentner, 2001). Research has identified that brighter colours such as red, orange, yellow, purple, blue, pink and green are more likely to be associated with positive emotions such as happiness, excitement and relaxation, whereas darker colours such as black, 
brown and grey are connected to more negative emotions like sadness, anger and boredom (Boyatzis and Varghese, 1994; Hemphill, 1996). Studies have ascertained that boys tend to have a less negative view of these darker colours and associate them less with negative feelings than girls (Boyatzis and Varghese, 1994; Hemphill, 1996; Zenter, 2001).

In previous studies using colour the participants were presented with a set number of colours (Boyatzis and Varghese, 1994; Hemphill, 1996; Wexner, 1954) ranging from eight (Wexner, 1954) to ten colours (Hemphill, 1996). Participants were asked when they were faced with a colour what was their emotional response to that colour (Hemphill, 1996). As the research participants in our study were aged 6-7, instead of expecting them to elicit a range of emotional responses to colours, we chose instead to identify in advance a list of 10 relatively simple emotions that participants may have experienced during the workshops and performances. We purposively chose pairs of positive and negative emotions as much as possible: Happy / Sad; Excited / Bored; Confident / Scared; Energy / Sleepy; Fun / Angry. We also chose to use words such as 'energy' rather than 'energetic', recognising that while the latter may be more usual to describe an emotion, the former may be more understandable to the young children participating in this research. Each child was provided with a sheet of paper, and a range of coloured crayons. The paper had been pre-printed with a row of 10 simple square boxes, one for each emotion we had identified. There were then 8 further square boxes, and participants were invited to identify, by use of the colours they had previously associated with a specific emotion, up to 4 emotions they had experienced at the participatory dance workshop and as audience members of the dance company's performance in the theatre that they had recently attended. The number of colours available to the children was to be limited as too many colours could create too many variables and confuse the results (Wexner, 1954). We based our selection of 8 potential colours on previous studies undertaken by Boyatiz and Varghese (1994) and Wexner (1954). When Punch (2002) conducted her research she found that when given free choice, the older children took their favourite colours leaving a limited amount of colours for the younger children. Our participants were 34 boys and 34 girls from 3 schools, and the research was conducted in each school as part of the participants' lesson time with teaching assistants helping the researcher in the classroom environment. Also in line with Boyatiz and Varghese's (1994) research, we first tested to ascertain a link between colour and emotional response by asking participants to colour in each square shape relating to each emotion we had identified, i.e. to fill in one square with whichever colour they associated with 'happy', another square for 'sad', and so on until all 
the emotional states we had identified were covered. We asked to select a different colour to represent each emotion (although as will be seen in the findings, most children followed the instructions, but some children chose to colour in certain of the squares with multiple colours). This enabled the researchers to draw inferences of meanings through the colours without expecting the young participants to make a verbal link between colours and emotional states. Having chosen which colours they associated with each emotion, next the participants were asked to identify which colours best represented up to 4 emotions they experienced in both the workshops and in the performance. The number of emotional responses they could each identify was limited in order to not confuse the young participants with an overly complex association exercise. Thus, if for example, in the first task a participant had coloured in 'excited' with the colour red, and 'bored' with the colour green, and then coloured in how they felt at the workshop as red and the performance as green, we could infer that the child was excited at the workshop and bored at the performance. Even if another child had identified these same emotions with different colours, for example, having chosen blue to represent 'excitement' and black to represent 'bored', we could still infer that this different child had experienced similar emotions to the other during the workshop and the performance despite the use of a different colour to represent the same emotion.

Colour and emotion are subjective and a participant's positive or negative reaction to a particular colour will be determined by their own experience relating to particular colours (Boyatiz and Varghese, 1994) and cannot be predetermined or known by the researcher. Therefore it was imperative that the elements which could be controlled were limited: colours, classroom environment, questions and data collection sheets. To ensure that the instruments used within this research study are reliable as possible, colours, question style/format/boxes were informed by literature. Moreover, also in line with previous research, 'in order to increase the validity of the findings each researcher analysed the data separately in order to identify indicative findings. Both researchers' interpretations of the data were in agreement, despite the very individual nature of interpretative research' (Skinner and Stephens, 2003:184).

This paper also aims to offer insights into the process of conducting an impact evaluation of a dance-theatre company's staged productions and workshops. In order to do this, the researchers chose to use the method of critical introspection. Both authors had practical 
experience gained within the performing arts prior to entering the world of academia, and so were able to perform the evaluation from a relatively informed perspective. It has been recognised that "many conventional research techniques incorporate introspective components without discussing the introspective implications or even mentioning them. On the other hand, a number of qualitative techniques are built on introspective procedures using the introspective process and discussing it but avoiding the name of introspection' (Kleining and Witt, 2000). This paper instead explicitly includes an introspective method of data collection based upon one of the researcher's attendance at one of the dance-theatre company's performance, designed to assess the impact of the performance on the child audience. This paper uses an accepted form of introspection in that did 'require inner observation' and the 'generation of descriptions and explanations' (Ericsson and Fox, 2011:351). As this research was concerned with not only evaluating the impact of the performing arts, but also with the act of performing arts impact evaluations, introspection seemed to be an appropriate method to use because it affords 'both a means of data collection and a means to study inner processes' (Kleining and Witt, 2001).

\section{Discussion of findings}

Firstly, highlights from the introspective account of one of the dance-theatre company's staged productions provided by one of the researchers are presented; secondly, we present results analysing children's emotional responses to their engagement with the company; and, finally, the critical reflection of the research process.

\section{Introspective account of performance}

One of the researchers attended one of the staged dance-theatre performances. The personal introspective account included notes concerning the venue: 'The theatre was quite old and a little run down, the stage had a simple set of three screens with a jumble of clothes around the screens and the perimeter of the stage'; the audience reaction 'When the lights went down it was pitch black, which made some of the children shout out "Woooo"'; and notes on the actual performance 'the performance started with the two dancers under the clothes playing a game of hide and seek with each other; the music was not recognisable as mainstream music but had lots of bells and chimes as if it was replicating school bells or to signal the start of something. Throughout the performance the style of dance portrayed a childlike quality that mimicked children's games such as "Tag", "Hide and Seek" and "Follow My Leader" which was performed with tons of energy and facial expressions. When interacting with the screens 
or the characters created on the screens the dancers stayed in a "childlike" character themselves and maintained a lot of eye contact and interaction with children. There were several different scenes throughout the performance with nearly all involving the three screens on the stage using either animation or shadows. All the animation was simple and uncomplicated ... The dancers interacted with all the animation on the screens. This ranged from creating magical underwater scenes where the dancers went deep sea swimming (at this some of the children shouted out "Wow") and played with star fish, strange bird animal like creatures where the birds flew across the screens and into the dancers pockets and also animated and shadow format versions of the dancers. Also the animation created some characters that were scary, there was a clothes monster (which looked like it could have been created by a child) which the dancers appeared to be afraid of and ran away only to realise that the monster was nothing to be scared of. The use of shadow play was also integrated into the performance, created through the use of 'either hand shadows or the dancers behind the screens, in particular when rabbits and cats were created using hands this really impressed the children as you could hear and see them pointing out the different animals'. The researcher summarised that 'On the whole the performance created a magical mystical place of imagination, wonder and make believe which involved the children in a world which they could relate to as the performance was performed in a childlike manner using mediums they are familiar with. It was clear that the children enjoyed the performance although after a while the children did become restless'.

\section{Children's emotional responses}

A simple frequency analysis was undertaken of the colouring sheets, identifying how many times any particular colour was chosen overall to represent an emotion (Table 2), and which colours were more frequently chosen by boys and which by girls (Table 3 ) - emboldened figures in Tables 2 and 3 highlight the colours most frequently representing an emotion; which emotions were more frequently associated with attendance at the dance-theatre company's staged production (Table 4) and if this differed between boys and girls (Table 5); which emotions were more frequently associated with participation in the workshops conducted in the schools (Table 6), and if this differed between boys and girls (Table 7).

Thus the results will be presented as simple frequency analyses of the number of occurring colours / emotions, making this more akin to the way texts are subject to a content analysis in order to 
quantitatively describe manifestations of the content of communication (Berelson, 1952), thus employing only a 'quasi-quantitative' method of analysing qualitative research, where results do not have to be subject to the same objective replicable statistical analyses as when conducting quantitative research (Hansen, Cottle, Negrine and Newbold, 1998), but where, instead, counting is being used to identify specific characteristics of communications (Holsti, 1969). In this case the specific characteristics are the various colours chosen by the research participants to communicate emotions.

Table 2: Colours chosen to represent emotions - overall

Table 3: Colours chosen to represent emotions - by boys and by girls

Table 4: Emotional responses to the performance - overall

Table 5: Emotional responses to the performance - by boys and by girls

Table 6: Emotional responses to the workshop - overall

Table 7: Emotional responses to the workshop - by boys and by girls

In keeping with earlier research (Boyatzis and Varghese, 1994; Hemphill, 1996) we found that the brighter colours children selected to identify specific emotional states tended to be associated more with positive emotions, whereas the darker colours tended to be associated more with negative emotional states. Thus, for example, 'happy' was most frequently associated with the colours red and yellow, 'sad' with black; red and purple were most frequently associated with 'excited', whereas brown and black were most frequently associated with 'bored'. Interestingly, some children chose to colour in the square with more than one colour to associate with 'scared' and with 'energy.

Participants were not required to fill in all four squares for performance or workshop. We can only speculate that a possible reason some children did not colour in all four squares is that they felt that they had fully expressed their emotions by colouring in fewer squares.

We also found some differences between the colours that girls and boys selected to represent emotional states (Hemphill, 1996; Boyatzis and Varghese, 1994; Zenter, 2001). Whereas both boys and girls more frequently associated red with 'happy' and black with 'sad', 'fun', for example, was more frequently associated with red and blue by girls, and with yellow and green by boys. 
We also found differences overall in children's emotional states with regard to the staged theatre performances compared with the workshops undertaken in schools. Overall, our participants felt happier, excited and more confident as creative participants in the workshops, and more sad, sleepy and bored as audience members of the theatre performances. Once again we found some differences between boys and girls, with boys more sad and sleepy in the performances compared to girls who identified the performance more frequently with emotions such as bored and angry. Boys more frequently associated their participation in the workshops with emotions such as 'sad', whereas girls identified 'confident' more frequently than boys, although the workshop activities were associated most frequently with emotions such as happy and excited by both boys and girls.

\section{Critical reflection of the research process}

\section{$\underline{\text { Research Design Limitations }}$}

There are a number of limitations to this study. Firstly, there will always be limitations regarding the use of single case based research. Secondly, our assessment of the soft outcomes contributing to the impact evaluation of the dance-theatre company's performances in school-based workshops was not really able to include views of the impact of these performances and workshops on the children because only 5 questionnaires were returned out of all that were distributed to teachers in the schools involved with this dance-theatre project. This would usually render results unusable, and certainly unable to be presented in quantifiable terms of percentages of research participants for academic publication purposes. However, in terms of the company's use of the results of such an impact evaluation, this did provide usable insights where the majority of teacher respondents 'strongly agreed' or 'agreed' that engagement with the activities had positive effects on the children, the school and on their own experiences as teachers. While teachers appeared to be happy to schedule in time for theatre attendance and time for dance workshops, scheduling time for the research to be undertaken was more problematic and support from the schools involved was patchy to say the least. This would appear to bear out Fineberg's (2105) belief that all parties should contractually agree their involvement prior to any arts programme being initiated. Had such a 
contract been in place that may have aided teachers' inputs into our evaluation. However, we were brought in once the programme had already been established, and the programme was not explicitly embedded in the curriculum, and involved only one theatre performance and one workshop per school.

\section{Conducting Research With Young Children}

Because we were not able to include the responses of teachers, our findings had to be based more heavily on the drawing method that was employed to collect data from the children themselves who had attended the performance as audience members, and the workshops as participants. Ethical clearances were not problematic as both researchers are familiar with the relevant university policies and processes in this respect, and the project gained ethical approval without issue. Schools were contacted by the company, and the researcher engaged support of classroom teachers to undertake the data collection.

It would not have been possible to ask such young children to provide a full service quality evaluation such as that undertaken by Hume and Mort (2008), neither would children this age be considered 'active, skilled and discerning' (Conway and Leighton, 2012). When considering the experiential and emotional aspect of our research participants, we ensured that there was a very short time in between the children attending the performance and participating in the workshops and the actual data collection, thus attempting to ensure the capture of short-lived experiential and episodic memory (Wood and Moss, 2015). We also had to employ more creative methods of data collection, not only because of the nature of the participatory creative experience (Douglas et al, 2000; Patton, 1987), but also because of the very young age of our research participants.

The relationship between the evaluators / researchers and the company

Devising innovative data collection methods was also, at least in part driven by costs. The company was not prepared to fund the project to purchase any of the soft outcome measurement tools identified by Anderson (2008), even though some of these are relatively inexpensive. However, as marketing academics we did not feel we faced problems in assessing soft, subjective, qualitative issues, as this is often part and parcel of marketing research, and believe that the results, bearing out earlier research involving the methods we used, offers a post-hoc justification of our initial confidence in our methods. 
We also found out very late on in our evaluation that a member of the dance-theatre company had the academic research skills to undertake such an activity, which is contrary to Fineberg's (2105) beliefs about the skills of artists as evaluators. However the company believed a third party evaluation may carry more weight when presented to potential future funders, which is wholly in keeping with Fineberg's beliefs that bringing in third party external evaluators can counter the arts organisation's 'self-proclaimed clams'. While we believe that the evaluation could have possibly been easier to undertake, and even have been more effective had this information been divulged earlier in the process, we also understand why the organisation may have felt the need not to divulge this, either to maintain a distance from the evaluation itself, or to ensure their own limited company resources were not diverted from their more core artistic and creative efforts.

\section{Academic Implications}

The use of a drawing method of data collection with these very young participants allowed the use of a creative method that better mirrors arts practice (Fillis, 2011) than management research, although this paper identifies a number of other creative methods that could align with those already familiar to management researchers.

The use of introspection by the academic researchers acting in the role of third-party impact evaluators helped overcome the challenges that would have been raised in asking such young children to evaluate not only the core performance and show experience, but also peripheral aspects of service quality (Hume and Mort, 2008).

The use of creative rather than more traditional research methods in this evaluative case study appeared to align well to an impact evaluation of an arts or cultural project (Douglas, Warwick, Whitty and Aggleton, 2000), and facilitated evaluation of soft aspects such as emotions of the research participants (Patton, 1987). Using such a method to elicit the emotions of the research participants also addresses calls for better understanding of consumer responses within the under-researched and relatively neglected realm of experiential marketing in the arts and cultural sectors (Conway and Leighton, 2012; Wood and Moss, 2015).

The implication we identify for furthering theoretical developments centres on ensuring that, when researching any form of cultural production, appropriate methods are used (Lawrence 
and Philips, 2002). However, in the main, business and management researchers may be more at home using methods such as surveys, interviews and focus groups, whereas, when performing arts evaluations, many other methods are available, including, for example, the use of story-telling, photo diaries, scrap books, feeling boxes, and indeed performances and presentations themselves, yet these methods tend to rest in the domain of arts rather than marketing research. We therefore strongly concur with Lawrence and Philips' (2002) contention that business and management researchers should therefore become more familiar with a wider range of research methods, and particularly when engaged in research into the performing arts.

\section{Practical Implications}

At the outset, this research project aimed to offer practical insights into various methods of impact evaluation that may be of particular use to smaller non-profit arts organisations who may be the ones most constrained by limited skills and financial resources. In doing so, by presenting the use of a drawing methodology, this paper has offered a method that that may help assess soft outcomes of arts and cultural projects involving young children. Furthermore, through the use of critical introspective into the process by which the impact evaluation in this particular case was conducted, the paper also offers a contribution in recognising the role of third-party evaluators, specifically academic researchers, in performing such impact evaluations.

Recognising the "technocratic "hoop[s]" that arts and cultural organisations now have to jump through in order to prove their worth and sustain funding, moving away from 'toolkit' based evaluations and rethinking evaluation as 'non-partisan ... critical practice' (Rooke, 2014) may also lead to an understanding of why this particular dance-theatre organisation sought their impact evaluation to be undertaken not only by an external third-party, but by academic researchers, even though in this case the organisation did have the skills to undertake this evaluation internally.

Issues arose in the process of conducting the evaluation that had the potential to strain the relationship between us as evaluators and the company as a client. Managers of organisations in the cultural and creative industries therefore need to ensure they select evaluators that will be sensitive to the nature of their industry, and understand their organisational limitations both 
in terms of skills and financial resources. Moreover, all parties to the evaluation should ensure that the resources put into the evaluation are of an appropriate level. As stressed by Fineberg (2015) 'for a modest program, consider a modest evaluaton and assessment process', and we believe we provided something of an appropriate size and scale, that met the requirements of our brief.

\section{Opportunities for Further Research}

A potentially fruitful area for further research may be to compare results from the use of a method using coloured drawing to elicit emotions with methods aimed at gathering verbal responses from young research participants in which they are simply asked about their emotional responses directly. This could further test and potentially strengthen the justification raised in this paper for the use of such a research method.

To strengthen the reliability of the results, when future studies include attendance at arts performances it may also be useful for more than one evaluator / researcher to attend such performances and compare their insights, recognising that they may have focused on different aspects of the performance, or have evaluated the same aspects differently.

While Daykin et al's (2008:251) study into 'the impact of participation in performing arts on adolescent health and behaviour' provided very useful background to our study, another potentially fruitful area for further research would be to undertake a more up to date systematic review of the literature since 2004 on the impact of the performing arts, either in general terms, or specifically in the contexts of their impacts on various groups of participants, as did Daykin et al, when considering the health and behavioural impacts of performing arts activities undertaken in school and community settings with young people aged 11-18.

\section{Conclusion}

The objectives of this research were to provide practical insights into various methods of impact evaluation that may be of particular use to smaller non-profit arts organisations, especially through the use of methods that assess soft rather than hard outcomes. The paper also sought to provide insights into the role of third-party evaluators in performing such impact evaluations. 
The extant literature has identified a wide range of methods that could be used, some more familiar to management researchers, others more familiar to those in the arts and cultural industries. One of the contributions this paper makes is not only in identifying this range of methods, but also in critically reflecting on our use of a creative method that is not only more appropriate to use with very young participants, but which is also more aligned to the arts than management research. The methods employed are also indicative of the way subjective soft outcomes can be evaluated, rather than the more objective hard outcomes so often prized by funding bodies.

It is recognised that performing arts impact evaluations are often driven by a need to evidence value for money to funders, yet many organisations involved in the performing arts rather see the value in arts for arts sake. However, being pragmatic, these organisations do understand that if they are to survive, especially in the current unstable economic environment where this sector is experiencing many cuts particularly in public sector funding, that evaluations are indeed hoops that need to be jumped through. We cannot comment on the extent to which arts organisations in general may value the results of evaluation exercises as a means of gaining feedback that could inform their future artistic practices, as this was outside the scope of what we researched. However, it was clear in the case of the project we evaluated that the outcome required by the organisation themselves was simply to result in an evaluation report that, especially through the employment of external third party academic evaluators, could better objectively evidence the value of the project to current funders as a way of ensuring positive responses when seeking future funding, and provide stronger evidence than the self-made claims the organisation may say about their own worth. The schools involved in taking their very young students to the dance-theatre performance and engaging the organisation to undertake workshops with their students did not seem to care about this evaluation project per $s e$. While the organisation deals with these educational establishments at a school level, it did seem that engagement with the programme and also with the evaluation itself was more driven by engagement of individual teachers at the classroom level. We had so few responses to the questionnaire we distributed that it is impossible to draw any valid inferences as to whether or not this lack of engagement with the evaluation reflected these stakeholders' perceptions as to the value of the actual performing arts project itself.

By focusing on the two approaches undertaken in this research project, the process of undertaking an impact evaluation, as well as the methods used to perform this evaluation, a 
further contribution made by this paper is in addressing some of the challenges of arts evaluations that otherwise may focus more on the process of implementing a project rather than on the project's performance or issues relating to participation in the project (Salmon, Kimberlee and Orme, 2004).

As researchers we recognise the benefits of our participation in this performing arts evaluation, not least in terms of contributing to furthering our understanding of management research into the cultural and creative industries. We also understand more about the tensions faced by marketers and managers in non-profit organisations in the cultural and creative industries when deciding whether to either undertake their own impact evaluation or outsource this activity to an objective third party.

In terms of relevance to arts management and arts marketing practice, we believe that when engaging third party impact evaluators that these should be chosen from subject disciplines that align with the issue to be evaluated. As marketing researchers we could draw from our experiences of researching consumer issues related to the commercial world outside of the cultural and creative industries. However, we also recognise that we may not have been engaged to undertake such an evaluation had we not had prior backgrounds in the performing arts, and that we were more able to offer a more informed evaluation because of this background.

\section{References}

Anderson, C. (2008). An overview of soft outcome / informal learning measurement tools. The Research \& Development Bulletin, 6(1), pp. 31-38.

Australia Council for the Arts. (2010). More than bums on seats: Australian participation in the arts, Sydney:Australia Council for the Arts.

Berelson, B., (1952). Content analysis in communication research. Glencoe, Ill.: Free Press

Boyatzis, C. J. and Varghese, R. (1994). Children's Emotional Associations with Colours. The Journal of Genetic Psychology, 155(1).Brennan, C. (2015). Arts cuts deaden our regions, The Guardian, 13 December 2015 [Internet] http://www.theguardian.com/commentisfree/2015/dec/13/arts-funding-cuts-regionsbadly-affected-econom-ic-stupidity [Accessed 24th February 2016]

Brewster, L. (2014). The Impact of Prison Arts Programs on Inmate Attitudes and Behavior: A Quantitative Evaluation. Justice Policy Journal, 11(2). 
Brown, M. (2015). Arts leaders relieved at better-than-expected funding agreement, The Guardian, 25 November 2015 [Internet] http://www.theguardian.com/culture/2015/nov/25/arts-council-museums-galleriesrelief-funding-settlement-autumn-statement [Accessed 24th February 2016]

Butcher, B. and Marsden, L. (2004). Measuring Soft Outomes: A Literature Review. The Research \& Development Bulletin 2(3), pp. 31-38.

Butler, P. (2013). Cuts may force councils to stop funding arts and leisure services by 2015. The Guardian, $28^{\text {th }}$ November 2013 [Internet] http://www.theguardian.com/society/2013/nov/28/local-council-funding-cuts-arts [accessed 22 May 2015]

Caust, J. (2003). Putting the "art" back into arts policy making: how arts policy has been "captured" by the economists and the marketers. International Journal of Cultural Policy, 9(1), pp. 51-63.

Child Trends (2010). Participation in School Music or Other Performing Arts. [Internet] www.childtrendsdatabank.org/?q=node/306 [Accessed 30th January 2012]

Conway, T. and Leighton, D. (2012). Staging the past, enacting the present, Arts Marketing: An International Journal, 2(1), pp. 35-51.

Daykin, N., Orme, J., Evans, D., Salmon, D., McEachran, M. and Brain, S. (2008) The impact of participation in performing arts on adolescent health and behaviour: A systematic review of the literature. Journal of Health Psychology, 13 (2), pp. 251-264.

Douglas, N., Warwick, I., Whitty, G. and Aggleton, P. (2000). Vital Youth: evaluating a theatre in health education project, Health Education, 100(5), pp. 207-215.

Ericsson, K.A., and Fox, M.C. (2011). Thinking aloud is not a form of introspection but a qualitatively different methodology: Reply to Schooler(2011), Psychological Bulletin, 137(2), pp. 351-354.

Fillis, I. (2011). The evolution and development of arts marketing research, Arts Marketing: An International Journal, 1(1), pp. 11-25.

Fineberg, C. (2015). Evaluation and Assessment: The Tail that Wags the Dog. [Internet] http://www.youngaudiences.org/why-arts/evaluation-and-assessment-tail-wags-dog [Accessed 15th May 2016]

Guillemin, M. (2004). Understanding Illness: Using Drawings as a Research Method, Qualitative Health Research, 14(2), pp.272-289.

Haber, R. N. and Hershenson, M. (1973). The Psychology of Visual Perception. New York:Holt, Rinehart and Winston Inc.

Hansen, A., Cottle, S., Negrine, R., and C. Newbold (1998). Mass Communication Research Methods. Hampshire: Macmillan Press Ltd 
Hemphill, M. (1996). A Note on Adults' Colour-Emotion Associations. The Journal of Genetic Psychology, 157(3).

Holsti, O.R. (1969). Content Analysis for the social sciences and humanities, Reading, Mass.: Addison-Wesley

Hume, M. and Mort, G.S. (2008). Satisfaction in performing arts: the role of value?, European Journal of Marketing, 42(3/4), pp. 311-326.

Jones, M., Murphy, S., Salmon, D., Kimberlee, R. and Orme, J. (2004). Implementing The Rock Challenge: teacher perspectives on a performing arts programme, Health Education, 104(6), pp. 351-359.

Kelly, A and Kelly, M. (2000). Impact and Values, Assessing the Arts and Creative Industries in the South West. Bristol:Bristol Cultural Development Partnership.

Kleining, G. and Witt, H. (2000). The Qualitative Heuristic Approach: A Methodology for Discovery in Psychology and the Social Sciences. Rediscovering the Method of Introspection as an Example, Forum: Qualitative Social Research-Sozialforschung, 1(1) article 13.

Kleining, G. and Witt, H. (2001). Discovery as a Basic Methodology of Qualitative and Quantitative Research. Forum: Qualitative Social Research - Sozialforschung, 2(1) article 16.

Kuhn, P. (2003). Thematic Drawing and Focused, Episodic Interview Upon the Drawing-A Method in Order to Approach to the Children's Point of View on Movement, Play and Sports at School, Qualitative Social Research, 4(1).

Landry, C., Bianchini, F., Maguire, M., and Worpole, K. (1993). The Social Impact of the Arts A Discussion Document, Stroud: Comedia.

Lawrence, T.B. and Philips, N. (2002). Understanding cultural industries. Journal of Management Inquiry, 11(4), pp. 430-441.

Lingayah, S., McGillivray, A., and Raynard, P. (1997). Creative Accounting: Beyond the bottom line, The Social Impact of the Arts, Working Paper 2, New Economics Foundation, Storud: Comedia.

Morgan, M., McInerney, F., Rumbold, J. and Liamputtong, P. (2008). Drawing the Experience of Chronic Vaginal Thrush and Complementary and Alternative Medicine, International Journal of Social Research Methodology, 12(2), p.p.127-146

O'Reilly, D. (2011). Mapping the arts marketing literature, Arts Marketing: An International Journal, 1(1), pp. 26-38.

Patton, M.Q. (1987). How To Use Qualitative Methods in Evaluation, Beverly Hills, CA:Sage Publications, 
Paul Hamlyn Foundation and NIACE (n.d). Evaluation Resource Pack [Internet] http://www.phf.org.uk/page.asp?id=933 [Accessed 5 ${ }^{\text {th }}$ January 2011]

Punch, S. (2002). Research with Children. The Same or Different from Research with Adults? Childhood, 9(3), pp.321-341.

Reeves, M. (2002). Measuring the economic and social impact of the arts. A review. Arts Council of England Research Report No.24. London: Arts Council England.

Rooke, A. (2014). This is not a toolkit: Reclaiming critical evaluation of participatory arts, XVIII ISA World Congress of Sociology: Facing an Unequal World-Challenges for Global Sociology, 13-19 July 2014, Yokohama [Internet] https://isaconf.confex.com/isaconf/wc2014/webprogram/Paper52806.html [Accessed 22 May 2015]

Skinner, H. and Stephens, P. (2003). Speaking the Same Language: Exploring the relevance of Neuro-Linguistic Programming to Marketing Communications. Journal of Marketing Communications 9(3), September 2003, pp. 177-192.

Tan, M. (2015). Dance rallies held across Australia protest $\$ 105 \mathrm{~m}$ cut to arts funding body, The Guardian, 22 May 2015 [Internet] http://www.theguardian.com/australianews/2015/may/22/dance-rallies-held-across-australia-protest-105m-cut-to-arts-fundingbody [accessed 28 May 2015]

Walmsley, B. (2013). "A big part of my life": a qualitative study of the impact of theatre, Arts Marketing: An International Journal, 3(1), pp. 73-87.

Wexner, L. B. (1954). The Degree to Which Colours (Hues) are Associated with MoodTones, The Journal of Applied Psychology, 38(6), pp.432-435.

Wood, E. (2005). Measuring the economic and social impacts of local authority events. International Journal of Public Sector Management, 18(1), pp. 37-53.

Wood, E.H. and Moss, J. (2015). Capturing emotions: experience sampling at live music events, Arts and the Market, 5(1), pp. 45-72.

Youngs, I. (2015). Arts Council boss makes funding plea. BBC News 28 May 2015 [Internet] http://www.bbc.com/news/entertainment-arts-32915647 [Accessed 28 May 2015]

Zentner, M. R. (2001). Preferences for Colours and Colour-Emotion Combinations in Early Childhood. Developmental Science, 4(4), pp.389-398. 
Table 1: Main themes arising in the arts evaluation literature

\begin{tabular}{|l|l|}
\hline \multicolumn{2}{|c|}{ Focus of evaluation } \\
\hline Accountability to funders & Anderson (2008) \\
& Caust (2003) \\
& Fillis (2011) \\
& Fineberg (2015) \\
& Kelly and Kelly (2000) \\
\hline Project implementation & Salmon, Kimberlee and Orme (2004) \\
\hline Achieving and evidencing 'value' & Anderson (2008) \\
& Hume and Mort (2008) \\
\hline Emotional, experiential and service & Conway and Leighton (2012) \\
aspects & Hume and Mort (2008) \\
& Patton (1987) \\
\hline Arts for arts sake vs. economic & Wood and Moss (2015) \\
rationality & Brewster (2014) \\
& Caust (2003) \\
& Kelly and Kelly (2000) \\
& Landry, Bianchini, Maguire and Worpole (1993) \\
& Lingayah, McGillivray and Raynard (1996) \\
& Reeves (2002) \\
& Walmsley (2013) \\
& Wood (2005) \\
\hline Results through the use of creative & Anderson (2008) \\
research methods & Douglas, Warwick, Whitty and Aggleton (2000) \\
& Fillis (2011) \\
& Patton (1987) \\
& Rooke (2014) \\
\hline
\end{tabular}


Table 2: Colours chosen to represent emotions - overall

\begin{tabular}{|c|c|c|c|c|c|c|c|c|c|c|c|c|c|c|c|c|c|c|c|c|}
\hline & \multicolumn{2}{|c|}{ Happy } & \multicolumn{2}{|c|}{ Sad } & \multicolumn{2}{|c|}{ Excited } & \multicolumn{2}{|c|}{ Bored } & \multicolumn{2}{|c|}{ Fun } & \multicolumn{2}{|c|}{ Angry } & \multicolumn{2}{|c|}{ Confident } & \multicolumn{2}{|c|}{ Scared } & \multicolumn{2}{|c|}{ Energy } & \multicolumn{2}{|c|}{ Sleepy } \\
\hline & $n$ & $\%$ & $n$ & $\%$ & $n$ & $\%$ & $n$ & $\%$ & $n$ & $\%$ & $\mathrm{n}$ & $\%$ & $n$ & $\%$ & $n$ & $\%$ & $\mathbf{n}$ & $\%$ & $n$ & $\%$ \\
\hline RED & 24 & 35.3 & 12 & 17.1 & 17 & 24.6 & 4 & 5.8 & 11 & 15.9 & 16 & 23.2 & 17 & 24.6 & 7 & 10.1 & 12 & 18.2 & 5 & 6.7 \\
\hline YELLOW & 18 & 26.5 & 3 & 4.3 & 10 & 14.5 & 10 & 14.5 & 14 & 20.3 & 4 & 5.8 & 15 & 21.7 & 3 & 4.3 & 5 & 7.6 & 7 & 9.3 \\
\hline BLUE & 13 & 19.1 & 4 & 5.7 & 10 & 14.5 & 7 & 10.1 & 10 & 14.5 & 5 & 7.2 & 12 & 17.4 & 9 & 13.0 & 11 & 16.7 & 11 & 14.7 \\
\hline GREEN & 2 & 2.9 & 2 & 2.9 & 8 & 11.6 & 11 & 15.9 & 15 & 21.7 & 9 & 13.0 & 6 & 8.7 & 7 & 10.1 & 12 & 18.2 & 6 & 8.0 \\
\hline PURPLE & 10 & 14.7 & 5 & 7.1 & 14 & 20.3 & 4 & 5.8 & 8 & 11.6 & 4 & 5.8 & 6 & 8.7 & 1 & 1.4 & 4 & 6.1 & 10 & 13.3 \\
\hline BROWN & 0 & 0.0 & 11 & 15.7 & 1 & 1.4 & 12 & 17.4 & 6 & 8.7 & 15 & 21.7 & 6 & 8.7 & 9 & 13.0 & 6 & 9.1 & 11 & 14.7 \\
\hline BLACK & 1 & 1.5 & 32 & 45.7 & 4 & 5.8 & 13 & 18.8 & 2 & 2.9 & 14 & 20.3 & 6 & 8.7 & 18 & 26.1 & 2 & 3.0 & 14 & 18.7 \\
\hline WHITE & 0 & 0.0 & 1 & 1.4 & 0 & 0.0 & 7 & 10.1 & 0 & 0.0 & 2 & 2.9 & 0 & 0.0 & 5 & 7.2 & 0 & 0.0 & 3 & 4.0 \\
\hline MULTI & 0 & 0.0 & 0 & 0.0 & 5 & 7.2 & 1 & 1.4 & 3 & 4.3 & 0 & 0.0 & 1 & 1.4 & 10 & 14.5 & 14 & 21.2 & 8 & 10.7 \\
\hline
\end{tabular}


Table 3: Colours chosen to represent emotions - by boys and by girls

\begin{tabular}{|c|c|c|c|c|c|c|c|c|c|c|c|c|c|c|c|c|c|c|c|c|c|}
\hline & & \multicolumn{2}{|c|}{ Happy } & \multicolumn{2}{|c|}{ Sad } & \multicolumn{2}{|c|}{ Excited } & \multicolumn{2}{|c|}{ Bored } & \multicolumn{2}{|c|}{ Fun } & \multicolumn{2}{|c|}{ Angry } & \multicolumn{2}{|c|}{ Confident } & \multicolumn{2}{|c|}{ Scared } & \multicolumn{2}{|c|}{ Energy } & \multicolumn{2}{|c|}{ Sleepy } \\
\hline RED & GIRLS & 12 & 35.3 & 3 & 8.3 & 7 & 20.0 & 3 & 8.6 & 8 & 22.2 & 9 & 25.7 & 7 & 20.6 & 4 & 11.4 & 5 & 15.6 & 3 & 8.6 \\
\hline YELLOW & GIRLS & 11 & 32.4 & 3 & 8.3 & 6 & 17.1 & 4 & 11.4 & 6 & 16.7 & 1 & 2.9 & 8 & 23.5 & 1 & 2.9 & 3 & 9.4 & 2 & 5.7 \\
\hline \multirow[t]{2}{*}{ BLUE } & BOYS & 10 & 29.4 & 2 & 5.9 & 6 & 17.6 & 4 & 11.8 & 2 & 6.1 & 0 & 0.0 & 8 & 22.9 & 3 & 8.8 & 7 & 20.6 & 6 & 16.7 \\
\hline & GIRLS & 3 & 8.8 & 2 & 5.6 & 4 & 11.4 & 3 & 8.6 & 8 & 22.2 & 5 & 14.3 & 4 & 11.8 & 6 & 17.1 & 4 & 12.5 & 5 & 14.3 \\
\hline \multirow[t]{2}{*}{ PURPLE } & BOYS & 3 & 8.8 & 4 & 11.8 & 1 & 2.9 & 3 & 8.8 & 3 & 9.1 & 2 & 5.9 & 5 & 14.3 & 0 & 0.0 & 0 & 0.0 & 4 & 11.1 \\
\hline & GIRLS & 7 & 20.6 & 1 & 2.8 & 13 & \begin{tabular}{|l|}
37.1 \\
\end{tabular} & 1 & 2.9 & 5 & 13.9 & 2 & 5.7 & 1 & 2.9 & 1 & 2.9 & 4 & 12.5 & 6 & 17.1 \\
\hline \multirow[t]{2}{*}{ BROWN } & BOYS & 0 & 0.0 & 8 & 23.5 & 0 & 0.0 & 4 & 11.8 & 3 & 9.1 & 7 & 20.6 & 1 & 2.9 & 7 & 20.6 & 3 & 8.8 & 3 & 8.3 \\
\hline & GIRLS & 0 & 0.0 & 3 & 8.3 & 1 & 2.9 & 8 & 22.9 & 3 & 8.3 & 8 & 22.9 & 5 & 14.7 & 2 & 5.7 & 3 & 9.4 & 4 & 11.4 \\
\hline BLACK & BOYS & 1 & 2.9 & 10 & 29.4 & 4 & 11.8 & 8 & 23.5 & 1 & 3.0 & 9 & 26.5 & 2 & 5.7 & 9 & 26.5 & 1 & 2.9 & 8 & 22.2 \\
\hline MULTI & GIRLS & 0 & 0.0 & 0 & 0.0 & 1 & 2.9 & 0 & 0.0 & 1 & 2.8 & 0 & 0.0 & 0 & 0.0 & 4 & 11.4 & 7 & 21.9 & 4 & 11.4 \\
\hline
\end{tabular}


Table 4: Emotional responses to the performance - overall

\begin{tabular}{|l|r|r|}
\cline { 2 - 3 } \multicolumn{1}{c|}{} & $\mathrm{n}$ & $\%$ \\
\hline Happy & 19 & 16.2 \\
\hline Fun & 19 & 16.2 \\
\hline Sad & 16 & 13.7 \\
\hline Sleepy & 14 & 12.0 \\
\hline Bored & 13 & 11.1 \\
\hline Excited & 12 & 10.3 \\
\hline Angry & 11 & 9.4 \\
\hline Confident & 6 & 5.1 \\
\hline Scared & 5 & 4.3 \\
\hline Energy & 2 & 1.7 \\
\hline
\end{tabular}

Total $\quad 117$

\section{8 emotions elicited per child}

Table 5: Emotional responses to the performance - by boys and by girls

\begin{tabular}{|l|r|r|r|r|}
\hline & \multicolumn{2}{|c|}{ Boys } & \multicolumn{2}{c|}{ Girls } \\
\hline & $\mathrm{n}$ & \multicolumn{1}{|c|}{$\%$} & $\mathrm{n}$ & \multicolumn{1}{c|}{$\%$} \\
\hline Sad & 10 & 20.8 & 13 & 18.8 \\
\hline Sleepy & 9 & 18.8 & 12 & 17.4 \\
\hline Happy & 7 & 14.6 & 10 & 14.5 \\
\hline Fun & 6 & 12.5 & 9 & 13.0 \\
\hline Confident & 4 & 8.3 & 9 & 13.0 \\
\hline Excited & 3 & 6.3 & 6 & 8.7 \\
\hline Bored & 3 & 6.3 & 5 & 7.2 \\
\hline Angry & 2 & 4.2 & 3 & 4.3 \\
\hline Energy & 2 & 4.2 & 2 & 2.9 \\
\hline Scared & 2 & 4.2 & 0 & 0.0 \\
\hline Total & 48 & & 69
\end{tabular}


Table 6: Emotional responses to the workshop - overall

Table 6: Emotional responses

to the workshop - overall

\begin{tabular}{|l|r|r|}
\hline & \multicolumn{1}{|c|}{$\mathrm{n}$} & \multicolumn{1}{c|}{$\%$} \\
\hline Happy & 27 & 20.0 \\
\hline Excited & 24 & 17.8 \\
\hline Fun & 18 & 13.3 \\
\hline Confident & 17 & 12.6 \\
\hline Sad & 12 & 8.9 \\
\hline Sleepy & 11 & 8.1 \\
\hline Angry & 8 & 5.9 \\
\hline Bored & 7 & 5.2 \\
\hline Energy & 6 & 4.4 \\
\hline Scared & 5 & 3.7 \\
\hline
\end{tabular}

Total $\quad 135$

\section{1 emotions elicited per child}

Table 7: Emotional responses to the workshop - by boys and by girls

\begin{tabular}{|l|r|r|r|r|}
\hline & \multicolumn{2}{|c|}{ Boys } & \multicolumn{2}{c|}{ Girls } \\
\hline & $\mathrm{n}$ & \multicolumn{1}{|c|}{$\%$} & $\mathrm{n}$ & \multicolumn{1}{c|}{$\%$} \\
\hline Happy & 13 & 20.3 & 14 & 19.7 \\
\hline Excited & 10 & 15.6 & 14 & 19.7 \\
\hline Sad & 8 & 12.5 & 11 & 15.5 \\
\hline Fun & 7 & 10.9 & 11 & 15.5 \\
\hline Confident & 6 & 9.4 & 5 & 7.0 \\
\hline Sleepy & 6 & 9.4 & 4 & 5.6 \\
\hline Energy & 5 & 7.8 & 4 & 5.6 \\
\hline Angry & 4 & 6.3 & 4 & 5.6 \\
\hline Bored & 3 & 4.7 & 3 & 4.2 \\
\hline Scared & 2 & 3.1 & 1 & 1.4 \\
\hline
\end{tabular}

Total

64

71 